\title{
DISTRIBUIÇÃO DE ELEMENTOS TRAÇO EM TECIDOS DE Goniopsis cruentata (LATREILLE, 1803) CAPTURADOS NOS MANGUEZAIS DO SUL DA BAHIA - BRASIL E AVALIAÇÃO DO POTENCIAL DE RISCO NO CONSUMO
}

\author{
Luanna M. Carneiro ${ }^{a}$, Danilo J. G. da Silva ${ }^{\mathrm{b}}$, Luan C. G. dos Reis ${ }^{\mathrm{a}}$, Daiane A. F. de Oliveira ${ }^{\mathrm{a}}$, Laís da C. Maciel ${ }^{\mathrm{b}}$, Karina \\ S. Garcia ${ }^{a}$, Sarah A. R. Soares ${ }^{\mathrm{a}, *}$ e Antônio F. de S. Queiroz ${ }^{\mathrm{a}}$ \\ ${ }^{a}$ Departamento de Oceanografia, Instituto de Geociências, Universidade Federal da Bahia, 40170-115 Salvador - BA, Brasil \\ bUniversidade Salvador, 41940-560 Salvador - BA, Brasil
}

Recebido em 22/01/2018; aceito em 25/06/2018; publicado na web em 14/08/2018

\begin{abstract}
DISTRIBUTION OF TRACE ELEMENTS IN TISSUES OF Goniopsis cruentata (LATREILLE, 1803) CAUGHT FROM SOUTH OF BAHIA/ BRAZIL MANGROVES AND POTENTIAL OF RISK ASSESSMENT IN CONSUMPTION. The concentrations of trace metals $\mathrm{Ba}, \mathrm{Cd}, \mathrm{Co}, \mathrm{Cr}, \mathrm{Cu}, \mathrm{Mn}, \mathrm{Mo}, \mathrm{Ni}, \mathrm{Pb}, \mathrm{Zn}$ and $\mathrm{V}$ were measured in gills, muscle and hepatopancreas of $G$. cruentata caught from South of Bahia in order to assess the potential health risk by the consumption of mangrove crabs. The highest metal concentrations in gills, and hepatopancreas were $\mathrm{Cu}$, and $\mathrm{Zn}$ in muscles, while the lowest metal concentration in three tissues was $\mathrm{Cd}$ and Mo. With the results, it is possible to suggest that the high concentrations of some elements, especially of the $\mathrm{Cu}$, may present risks to the Aratu consumers of the mangrove areas studied, or to other populations where these animals may be transported, same for other cities. The mean concentration of $\mathrm{Pb}$ in gills in Una and Jequitinhonha is above the value allowed by the legislation, 3,08 $\mu \mathrm{g} \mathrm{g}^{-1}$ and 3,49 $\mu \mathrm{g} \mathrm{g}^{-1}$, respectively. The concentration of $\mathrm{Mn}$ in the females in the three estuaries studied was 1.5 to 4.2 times higher than in the males. In general, detected mean metal concentrations in crab tissues were (in decreasing order) gills $>$ hepatopancreas $>$ muscles. Through the PCA analysis, differentiation between the tissues studied was observed due to its elemental composition. The target hazard quotient $(\mathrm{QR})$ of all trace metals in muscle was less than 1.0 of the provisional tolerable daily intake (IDE) adopted by the USEPA. These results imply that G. cruentata caught from South of Bahia do not have an adverse impact on the consumer health.
\end{abstract}

Keywords: Aratu; health risks; gills; hepatopancreas; muscles.

\section{INTRODUÇÃO}

O avanço da tecnologia, bem como o aumento da população, levou a preocupações ambientais relacionadas ao despejo indiscriminado de lixo e descarga de efluentes industriais, ${ }^{1}$ visto que as principais fontes de contaminação responsáveis pelo aumento nos níveis de contaminantes são a entrada indústria química, fabricação de papel, vazamento de oleoduto de campo de petróleo, ${ }^{2}$ somados à deposição atmosférica, erosão da matriz geológica e resíduos minerais. A descarga desses resíduos sem tratamento adequado geralmente contamina o ambiente estuarino, tanto a água como o sedimento e, consequentemente, a biota que retêm a parcela de contaminantes biodisponíveis. ${ }^{3}$

Elementos químicos estão presentes naturalmente na crosta terrestre e podem entrar nos ciclos de água e alimentos através de uma variedade de processos químicos e geoquímicos no ambiente, sendo alguns deles essenciais à vida em níveis baixos, mas tóxicos em maior concentração. ${ }^{1}$ Os metais não são biodegradáveis e, como consequência, se acumulam em tecidos vivos. ${ }^{2} \mathrm{O}$ processo de bioacumulação de metais pesados é a acumulação líquida de um metal no tecido de interesse ou todo o organismo que resulta de todos os meios de exposição ambiental, incluindo ar, água, fases sólidas e dieta. ${ }^{1}$ Além disso, depende também de fatores biológicos, como tamanho, idade, hábito de alimentação, temperatura e oxigênio dissolvido. ${ }^{4}$ Devido à bioacumulação em ecossistemas aquáticos ocorre a concentração ao longo da cadeia alimentar. ${ }^{2}$

Sabe-se que certas formas de metais podem se acumular facilmente dentro de tecidos de crustáceos em níveis muito mais altos do que aqueles na coluna d'água e em sedimentos. Para a fauna, as espécies mais estudadas são os macroinvertebrados bentônicos,

*e-mail: sarah.ufba@yahoo.com.br particularmente aqueles com baixa mobilidade. Estes acumulam maiores concentrações de metais em comparação com os animais que vivem em águas abertas, além de se alimentarem de presas bentônicas que vivem também em contato com o sedimento, podendo ser bons indicadores de qualidade ambiental uma vez que refletem os níveis contaminantes no sedimento superficial. ${ }^{2,4}$

Assim, estudos sobre a acumulação de metal em vários órgãos dos caranguejos podem fornecer conhecimentos adicionais sobre a correlação entre o organismo e o ambiente em que vivem. Diferentes tipos de tecido são frequentemente estudados por conterem diferentes concentrações de metal. ${ }^{2}$ Para os animais marinhos, as brânquias são cruciais para a respiração, a excreção, o equilíbrio ácido-base e a regulação osmótica e iônica. Em comparação com outras partes do corpo cobertas pelo exoesqueleto fornecendo a primeira proteção em crustáceos, as brânquias são a parte do corpo que são imediatamente expostas ao ambiente externo e, consequentemente, os primeiros a serem expostos a poluentes, como metais pesados. ${ }^{5}$

O hepatopâncreas nos crustáceos é um órgão análogo ao fígado, combinando as funções do fígado, pâncreas e intestino de vertebrados. ${ }^{6-8}$ Investigações anteriores sobre a estrutura, desenvolvimento, fisiologia, metabolismo e bioquímica do hepatopâncreas incluíram também como função desse órgão a absorção, digestão, armazenamento e secreção de substâncias. ${ }^{5,7}$ Segundo Corrêa Jr. et al. ${ }^{9} \mathrm{e}$ Bryan, ${ }^{10} \mathrm{o}$ hepatopâncreas também é capaz de realizar a emulsificação e absorção de nutrientes da dieta, regulação da concentração iônica celular e da hemolinfa, através de processos de absorção e secreção, como também pela estocagem de metais.

O músculo é um tecido caracterizado por elevado número de mitocôndrias, que também participam do sequestro de metais. ${ }^{11}$ Segundo Jesus et al.,${ }^{12}$ os metais, dependendo da sua condição de ser essencial ou não para o organismo, acumulam-se em tecidos 
diferentes, sendo que os essenciais são concentrados no músculo e, de acordo com Corrêa Jr et al., ${ }^{9}$ o acesso de contaminantes a órgãos internos, como o hepatopâncreas e o músculo, parece ser principalmente realizado por hemolinfa devido à baixa permeabilidade da carapaça e que esta relativa impermeabilidade do exoesqueleto cuticular poderia representar uma pré-adaptação à regulação do metal em decápodos.

A Análise de Componentes Principais (PCA, do inglês Principal Component Analysis) é uma ferramenta que possibilita uma visualização gráfica dos dados, aumentando a compreensão do conjunto de dados em diferentes áreas da ciência. ${ }^{13}$ A PCA tem sido utilizada por diversos autores ${ }^{13-15}$ para verificar a similaridade entre amostras através da sua composição química. A avaliação das componentes principais pode imprimir uma assinatura química para cada grupo de amostras, permitindo a visualização de informações mais facilmente do que se fosse utilizada a análise univariada. ${ }^{13}$

O Goniopsis cruentata (Aratu) (LATREILLE, 1803), usado como matriz biológica no presente estudo, possui importância econômica na região Nordeste do Brasil, incluindo as regiões de Una, Belmonte e Canavieiras, Sul da Bahia, sendo utilizado como fonte de alimento. ${ }^{16}$

Por ser um organismo bastante utilizado fonte de alimento para a população ribeirinha, se faz necessário o estudo do fator de risco devido ao consumo do músculo do G. cruentata, visto que mesmo elementos essenciais podem ser tóxicos quando ingeridos em grandes concentrações. ${ }^{17} \mathrm{O}$ risco para a saúde humana pode ser avaliado com base na ingestão diária tolerável provisória (IDTP), na ingestão diária estimada (IDE) e na dose de referencia diária (DRf) estabelecidas pela Agência de Proteção Ambiental dos Estados Unidos (USEPA, do inglês, United States Environmental Protection Agency) e pelo Comitê Misto de Peritos da Organização das Nações Unidas para Agricultura e Alimentação (FAO, do inglês, Food and Agriculture Organization) e Organização Mundial da Saúde sobre
Aditivos Alimentares (JECFA, do inglês, Joint FAO/WHO Expert Committee on Food Additives). ${ }^{17}$

Nesse estudo, foram investigadas as concentrações de onze elementos traço ( $\mathrm{Ba}, \mathrm{Cd}, \mathrm{Co}, \mathrm{Cr}, \mathrm{Cu}, \mathrm{Mn}, \mathrm{Mo}, \mathrm{Ni}, \mathrm{Pb}, \mathrm{Zn}$ e V) em tecidos de $G$. cruentata coletados em três diferentes estuários do Sul da Bahia. O objetivo primário desse estudo foi avaliar até que ponto esses caranguejos estão contaminados pelos metais selecionados. Além disso, o risco potencial à saúde humana também foi calculado para avaliar se o consumo de Aratu apresenta risco para a saúde dos consumidores do músculo. Esse estudo possibilitará investigar a segurança da ingestão diária, por seres humanos, de um organismo a partir do acúmulo de metais no mesmo.

\section{MATERIAIS E MÉTODOS}

\section{Caracterização da área de estudo}

O estudo foi realizado no trecho costeiro que pertence à denominada Costa do Cacau, ${ }^{18}$ situada na região sul do Estado da Bahia. Compreendeu o baixo curso dos rios Jequitinhonha, Una e Pardo, abrangendo os municípios de Belmonte, Una e Canavieiras, respectivamente ${ }^{19}$ com extensão superior a $164 \mathrm{~km}$. Foi realizada uma coleta em maio de 2013, sendo todos os pontos amostrados georeferenciados conforme Figura 1.

\section{Amostragem}

Em cada manguezal, foram amostrados seis pontos, sendo coletados 20 animais (10 fêmeas e 10 machos) em cada ponto, somando um total de 120 amostras para cada região. Os indivíduos foram coletados por marisqueiras da região, utilizando varas de bambu presas com linha de náilon com tecidos de animais mortos preso no anzol.

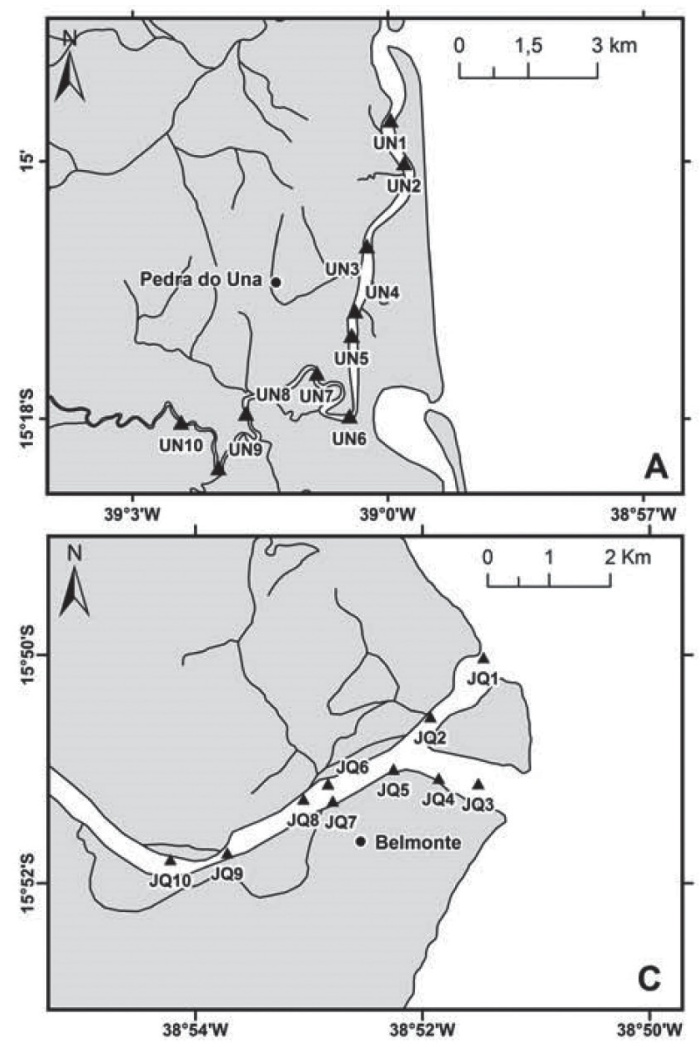

Figura 1. Mapa de localização dos Municípios de Una (Rio Una), Canavieiras (Rio Pardo) e Belmonte (Rio Jequitinhonha), e dos pontos de amostragem, em seus manguezais, canais estuarinos e praias. 


\section{Procedimentos analíticos}

A descontaminação de todo material utilizado nas etapas de coleta e análise foi realizada com Extran 0,5\% ( $\left.\mathrm{v} \mathrm{v}^{-1}\right)$ e ácido clorídrico $(\mathrm{HCl}) 10 \%\left(\mathrm{v} \mathrm{v}^{-1}\right)$. Para as análises químicas foram utilizados os ácidos nítrico $\left(\mathrm{HNO}_{3}\right)$ e sulfúrico $\left(\mathrm{H}_{2} \mathrm{SO}_{4}\right)$, bem como o peróxido de hidrogênio $\left(\mathrm{H}_{2} \mathrm{O}_{2}\right)$, de grau analítico (Merck, Alemanha). A água ultrapura utilizada foi obtida utilizando-se o sistema de ultrapurificação da Millipore (Merck, Alemanha). A solução padrão $1000 \mathrm{mg} \mathrm{L}^{-1}$, contendo os elementos que foram determinados, foi obtida da Merck (Merck, Alemanha). Foi utilizado o programa STATISTICA ${ }^{\circledast} 8.0$ para Windows no tratamento estatístico dos dados e Excel para geração dos gráficos.

\section{Análise biomética}

Realizou-se a sexagem, biometria e dissecação dos indivíduos capturados. Para a análise biométrica foram separadas dez amostras de Aratus machos e dez de Aratus fêmeas, por ponto, em cada estuário. Utilizou-se paquímetro (SOMET, precisão $0,1 \mathrm{~mm}$ ) para medidas do comprimento do cefalotórax (CC) e largura do cefalotórax (LC). A dissecação foi realizada na região cefalotoráxica de cada animal, utilizando uma tesoura de material inoxidável para remoção da carapaça.

\section{Determinação de elementos traço}

Neste estudo utilizou-se brânquias, músculo e hepatopâncreas dos animais, sendo que cada tecido seguiu uma metodologia de digestão diferente. Após a dessecação as 360 amostras de Aratus foram congeladas, em seguida liofilizadas (Liotop, modelo L101) por 120 horas, maceradas com grau e pistilo de ágata e mantidas em dessecador até a etapa de digestão ácida. Para a digestão de amostras de hepatopâncreas, pesou-se cerca de $0,1 \mathrm{~g}$ do tecido em um tubo de vidro, adicionou-se $1,0 \mathrm{~mL}$ de $\mathrm{H}_{2} \mathrm{SO}_{4}$ concentrado e em seguida, aqueceu-se em bloco digestor (Tecnal TE-007D) à $100{ }^{\circ} \mathrm{C}$ por aproximadamente $2 \mathrm{~h}$. À temperatura ambiente, acrescentou-se $1,5 \mathrm{~mL}$ de $\mathrm{HNO}_{3}$ concentrado, aquecendo-se novamente a $200{ }^{\circ} \mathrm{C}$ por $3 \mathrm{~h}$. Em seguida, transferiu-se para um frasco de polietileno levando-se a volume de 15,0 $\mathrm{mL}$ com água ultrapura. Para a digestão das brânquias e músculo foi pesado $0,1 \mathrm{~g}$ de amostra do tecido macerado e colocado em um tubo de vidro. Adicionaram-se 2,0 mL de $\mathrm{HNO}_{3}$ concentrado e aqueceu-se a amostra em bloco digestor à $150{ }^{\circ} \mathrm{C}$ por $2 \mathrm{~h}$. À temperatura ambiente, acrescentou-se $1,0 \mathrm{~mL}$ de $\mathrm{H}_{2} \mathrm{O}_{2}$ e aqueceu-se novamente a $150^{\circ} \mathrm{C}$ por $1 \mathrm{~h}$. Fez-se transferência para frasco de polietileno, sendo levado a volume até $15,0 \mathrm{~mL}$ com água ultrapura.

A determinação dos elementos foi realizada por Espectrometria de Emissão Óptica com Plasma Acoplado Indutivamente (ICP OES, do inglês, Inductively Coupled Plasma Optical Emission Spectrometry) (Agilent, 720 Series). Foram preparadas soluções de calibração multielementares com concentração variando de 0,05 a $5 \mathrm{mg} \mathrm{L}^{-1}$ com acidez compatível com a acidez final das amostras, utilizando o mesmo ácido/mistura ácida que foi utilizada durante o preparo das amostras.

Para o cálculo do limite de detecção e de quantificação das medidas recomenda-se utilizar o conceito de BEC (concentração equivalente ao sinal de fundo), ou seja, a concentração do analito que produz sinal equivalente à intensidade de emissão do fundo na linha medida. ${ }^{20} \mathrm{O}$ cálculo do BEC e dos limites de detecção (LOD) e de quantificação (LOQ) foram determinados de acordo com recomendações da União Internacional de Química Pura e Aplicada (IUPAC), ${ }^{20}$ sendo BEC $=$ Crs $/$ SBR e SBR = (Irs - Ibranco $) /$ Ibranco, em que Crs é a concentração da solução de referência, SBR é a relação sinal/ ruído, Irs e Ibranco, a intensidade de emissão da solução de referência e do branco, respectivamente. O LOD foi calculado como ( 3 x BEC $\mathrm{x}$ RSD)/ 100, em que RSD é o desvio padrão correspondente a 10 medidas da emissão da solução em branco para cada elemento. $\mathrm{O}$ LOQ foi calculado como (10 x BEC x RSD)/ 100. As condições de operação do equipamento, bem como limites de quantificação do método, estão descritos na Tabela 1 .

Tabela 1. Parâmetros instrumentais do ICP OES utilizado para a determinação de elementos traço em brânquias, hepatopâncreas e músculos de Aratu coletados no Sul da Bahia

\begin{tabular}{|c|c|}
\hline Parâmetros & Características \\
\hline Câmara de nebulização & Ciclônica (Single Pass) \\
\hline Nebulizador & SeaSpray \\
\hline Potência (kW) & 1.1 \\
\hline Vazão do gás do plasma $\left(\mathrm{L} \mathrm{min}^{-1}\right)$ & 15 \\
\hline Vazão do gás auxiliar $\left(\mathrm{L} \mathrm{min}^{-1}\right)$ & 1.5 \\
\hline Vazão do gás de nebulização $\left(\mathrm{L} \mathrm{min}^{-1}\right)$ & 0.75 \\
\hline $\begin{array}{l}\text { Elementos e comprimentos de onda } \\
\qquad(\mathrm{nm})\end{array}$ & $\begin{array}{l}\text { Ba II (455.403); Cd II (226.502); } \\
\text { Co II (228.615); Cr II (267.716); } \\
\text { Cu I (324.754); Mo II (204.598); } \\
\text { Mn II (257.610); Ni II (231.604); } \\
\text { Pb II (220.353); V II (311.837); } \\
\text { Zn I (213.857) }\end{array}$ \\
\hline Limites de quantificação $\left(\mu \mathrm{g} \mathrm{g}^{-1}\right)^{*}$ & $\begin{array}{c}\mathrm{Ba}(0.57) ; \mathrm{Cd}(0.37) ; \mathrm{Co}(0.14) ; \\
\mathrm{Cr}(0.21) ; \mathrm{Cu}(0.33) ; \mathrm{Mo}(0.44) ; \\
\mathrm{Mn}(0.26) ; \mathrm{Ni}(0.12) ; \mathrm{Pb}(0.15) \\
\mathrm{V}(0.22) ; \mathrm{Zn}(0.14)\end{array}$ \\
\hline
\end{tabular}

*calculados a partir do BEC. ${ }^{20}$

\section{Análise estatística}

O software Statistica foi usado para análises estatísticas univariadas. Todos os dados foram primeiramente testados quanto à normalidade e homogeneidade para conhecimento da demanda estatística. Análise ANOVA foi utilizada para comparar os resultados entre os grupos de caranguejo. Diferenças entre as médias foram consideradas significantes quando $\mathrm{p}<0.05$. Análise de Componentes Principais (ACP) foi utilizada para avaliar a diferença na concentração do elemento traço nos diferentes locais de coleta e tecidos do Aratu.

\section{Avaliação do potencial de risco}

Para estimar o efeito prejudicial à saúde humana por consumo do Aratu, a avaliação de risco potencial foi realizada no músculo dos caranguejos. Neste estudo, utilizamos a dose de referência (DRf) de $\mathrm{Cu}, \mathrm{Mn}$ e Zn recomendada pela Agência de Proteção Ambiental dos EUA. ${ }^{21,22}$

\section{RESULTADOS E DISCUSSÃO}

\section{Análise biométrica}

Foram medidos os parâmetros biométricos dos caranguejos da espécie G. cruentata, por sexo, na sua condição inicial. Os exemplares capturados exibiram largura de carapaça (LC) no intervalo entre 34,9 e $47,5 \mathrm{~mm}$, comprimento de carapaça (CC) entre 34,4 e $39,1 \mathrm{~mm}$ e peso úmido (PU) de 31,4 - 49,7 g, cujos resultados encontram-se dispostos na Tabela 2.

A partir da Análise de Variância (ANOVA) verificou-se que no rio Una somente o comprimento da carapaça não teve diferença significativa entre os sexos $(\mathrm{p}=0,060853)$, porém peso e largura de carapaça foram considerados significativamente diferentes. No rio Jequitinhonha a largura e o comprimento da carapaça não tiveram diferença significativa entre os $\operatorname{sexos}(p=0,120645$ e $p=0,078061$, respectivamente), apenas o peso mostrou diferença significativa. Já 
Tabela 2. Dados biométricos médios e desvio-padrão, por sexo, para caranguejos da espécie G. cruentata $(\mathrm{n}=6)$ coletados no sul da Bahia.

\begin{tabular}{|c|c|c|c|c|c|}
\hline Local de amostragem & $\mathrm{n}$ & Sexo & Largura da carapaça $(\mathrm{mm})$ & Comprimento da carapaça $(\mathrm{mm})$ & Massa total do Aratu (g) \\
\hline \multirow{2}{*}{ Rio Una } & 6 & Macho & $42 \pm 3$ & $36 \pm 3$ & $36 \pm 9$ \\
\hline & 6 & Fêmea & $39 \pm 3$ & $32 \pm 2$ & $25 \pm 7$ \\
\hline \multirow{2}{*}{ Rio Pardo } & 6 & Macho & $41 \pm 2$ & $34 \pm 2$ & $31 \pm 6$ \\
\hline & 6 & Fêmea & $39 \pm 1$ & $32 \pm 1$ & $23 \pm 2$ \\
\hline \multirow{2}{*}{ Rio Jequitinhonha } & 6 & Macho & $43 \pm 3$ & $35 \pm 3$ & $35 \pm 9$ \\
\hline & 6 & Fêmea & $41 \pm 3$ & $33 \pm 3$ & $27 \pm 4$ \\
\hline
\end{tabular}

no rio Pardo não houve diferença significativa nos valores médios dos dados biométricos entre os sexos. Não foi observada diferença significativa nos dados biométricos para as diferentes áreas estudadas $(\mathrm{p}=0,117)$.

Através da análise biométrica das amostras foi verificado que, para algumas variáveis nos manguezais, não há dimorfismo sexual quando estudado largura, comprimento e peso dos G. cruentata, como comprovado pela análise de variância (ANOVA). Menezes et al. ${ }^{23}$ ao estudar o G. cruentata no Complexo Estuarino Lagunar Mundaú - Alagoas, encontrou diferença significativa entre essas três variáveis em relação ao sexo nas estações de estudo, sendo as médias das medidas de LC, CC e PU, respectivamente de machos $29,89 \mathrm{~mm}$, $25,18 \mathrm{~mm}$ e $15,04 \mathrm{~mm}$ e para fêmeas $28,86 \mathrm{~mm}, 24,14 \mathrm{~mm}$ e 12,09 $\mathrm{mm}$. Pinheiro et al. ${ }^{24}$ ao estudarem o Ucides cordatus (Crustacea ucididae), constataram que a biometria dos caranguejos não diferiu estatisticamente em função do tamanho, quando os animais foram comparados entre Juréia, Itatins e Cubatão, regiões relativamente próximas. Nos manguezais estudados, a média da largura da carapaça (LC) está acima da média encontrada por Reis et al. ${ }^{25}$ que, ao estudarem o G. cruentata no sudeste do Brasil, encontraram médias para machos e fêmeas de $32,3 \mathrm{~mm}$ com desvio de, respectivamente, 7,5 e 6,8 .

Menezes et al., ${ }^{23}$ ao analisarem o mesmo caranguejo no complexo estuarino lagunar Mundaú/ Manguaba, Alagoas, verificaram a presença de fêmeas ovígeras praticamente o ano todo, com picos em alguns meses. Santos et al. ${ }^{26}$ ao estudarem a maturidade sexual do Aratu no manguezal de Caravelas-BA, também verificou a presença de fêmeas ovígeras praticamente todo o ano, porém a maior incidência foi entre janeiro e março, caracterizando a reprodução como sazonal contínua e, aliado a isso, não encontraram diferenças significativas da largura da carapaça entre machos e fêmeas nos meses de maio e junho, assim como o presente estudo. Ainda segundo o mesmo autor, no período de reprodução as fêmeas tendem a ficar menores do que os machos, devido a dinâmica reprodutiva, podendo justificar a ausência de dimorfismo sexual em relação à carapaça encontrada no presente estudo, já que a coleta foi realizada em maio, mês em que não foram verificadas fêmeas ovígeras.

\section{Determinação dos elementos traço}

Foram determinadas as concentrações dos elementos traço $\mathrm{Ba}$, $\mathrm{Cd}, \mathrm{Co}, \mathrm{Cr}, \mathrm{Cu}, \mathrm{Mn}, \mathrm{Mo}, \mathrm{Ni}, \mathrm{Pb}, \mathrm{Zn}$ e V, nas brânquias, hepatopâncreas e músculo dos Aratu capturados. Além das amostras, em triplicata, foram analisados brancos e os materiais de referência (NIST 1566b - Oyster Tissue e TORT-2 - Lobster Hepatopancreas) para avaliar a precisão e exatidão do método, utilizando mesmo método de digestão para hepatopâncreas e músculo e determinação por ICP OES. Os resultados (Tabela 3) mostram boas recuperações com desvios de $2-15 \%$, utilizando a metodologia proposta para as amostras de diferentes tecidos de Aratu. De acordo com a Associação Oficial de Químicos Agrícolas (AOAC, do inglês, Association of Official Agricultural Chemists), ${ }^{27}$ a faixa de recuperação aceitável, para analitos com concentração variando de 0,1 a $1 \mu \mathrm{g} \mathrm{g} \mathrm{g}^{-1}$, é $80-110 \%$, e desvio padrão relativo 8-16\%.

As concentrações médias, por sexo, estão dispostas na Tabela 4. Em algumas amostras os elementos $\mathrm{Co}, \mathrm{Cr}, \mathrm{Ni}, \mathrm{Pb}$ e $\mathrm{V}$ estão abaixo

Tabela 3. Valores certificados e observados e porcentagem de recuperação dos elementos traço nos materiais de referência NIST 1566b (Oyster Tissue) e TORT-2 (Lobster Hepatopancreas)

\begin{tabular}{|c|c|c|c|c|c|c|c|c|c|c|}
\hline \multirow{2}{*}{ MRC } & & \multirow{2}{*}{$\mathrm{n}$} & \multicolumn{8}{|c|}{ Concentração $\left(\mu \mathrm{g} \mathrm{g}^{-1}\right)$} \\
\hline & & & $\mathrm{Al}$ & As & $\mathrm{Cd}$ & $\mathrm{Cu}$ & $\mathrm{Fe}$ & $\mathrm{Mn}$ & V & $\mathrm{Zn}$ \\
\hline \multicolumn{11}{|l|}{ NIST $1566 b$} \\
\hline \multirow[t]{2}{*}{ Valor certificado } & Média & 4 & 197.2 & 7.65 & 2.48 & 71.6 & 205.8 & 18.5 & 0.577 & 1424 \\
\hline & Desvio & & 6 & 0.65 & 0.08 & 1.6 & 6.8 & 0.2 & 0.023 & 46 \\
\hline \multirow[t]{3}{*}{ Valor medido } & Média & & 193.9 & 6.75 & 2.21 & 61.4 & 192.2 & 17.3 & 0.474 & 1390 \\
\hline & Desvio & & 7.8 & 0.46 & 0.09 & 2.1 & 6.7 & 0.6 & 0.012 & 22 \\
\hline & $\mathrm{R} \%$ & & 98 & 88 & 89 & 86 & 93 & 94 & 85 & 98 \\
\hline \multicolumn{11}{|l|}{ TORT - 2} \\
\hline \multirow[t]{2}{*}{ Valor certificado } & Média & 4 & ---- & 21.6 & 26.7 & 106 & 105 & 13.6 & 1.64 & 180 \\
\hline & Desvio & & & 1.8 & 0.6 & 10 & 13 & 1.2 & 0.19 & 6 \\
\hline \multirow[t]{3}{*}{ Valor medido } & Média & & ---- & NA & 25.1 & 104 & 100 & 12.8 & 1.52 & 171 \\
\hline & Desvio & & & & 0.1 & 1 & 8 & 0.6 & 0.03 & 3 \\
\hline & $\mathrm{R} \%$ & & & & 93 & 98 & 95 & 94 & 92 & 94 \\
\hline
\end{tabular}

$\mathrm{R}=$ recuperação; NA = não analisado. 
Tabela 4. Concentração média, mínima e máxima $(\mathrm{n}=6)$ de elementos traço, expressa em $\mu g \mathrm{~g}^{-1}$, para diferentes tecidos dos caranguejos da espécie $G$. cruentata coletados nos Estuários dos rios Una, Pardo e Jequitinhonha - Sul do Estado da Bahia

\begin{tabular}{|c|c|c|c|c|c|c|c|c|c|c|c|c|}
\hline \multirow{2}{*}{ Local } & \multirow{2}{*}{ Tecido } & \multirow{2}{*}{ Sexo } & \multirow{2}{*}{ Valores } & \multicolumn{9}{|c|}{ Concentração $\left(\mathrm{mg} \mathrm{g}^{-1}\right)$} \\
\hline & & & & $\mathbf{B a}$ & $\mathrm{Cu}$ & Co & Mn & $\mathrm{Ni}$ & V & Zn & $\mathrm{Cr}$ & $\mathbf{P b}$ \\
\hline \multirow{12}{*}{ 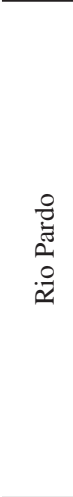 } & \multirow{4}{*}{ 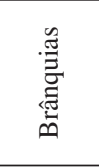 } & \multirow{2}{*}{ Macho } & Média & 10.2 & 201 & 1.17 & 39.7 & 2.46 & 14.9 & 43.6 & 4.82 & 3.04 \\
\hline & & & Min -Max & $6.13-13.5$ & $172-232$ & $0.66-1.59$ & $26.6-397$ & $2.15-2.71$ & $10.3-23.6$ & $38.1-50.7$ & $3.79-5.44$ & $3.47-3.59$ \\
\hline & & \multirow{2}{*}{ Fêmea } & Média & 11.4 & 181 & 1.53 & 103 & 2.45 & 20.4 & 45.5 & 5.07 & 4.04 \\
\hline & & & Min -Max & $7.05-17.4$ & $147-199$ & $0.72-3.52$ & 28.1-129 & $1.85-3.09$ & $10.7-23.6$ & $38.1-50.7$ & $3.51-6.89$ & $2.43-7.04$ \\
\hline & \multirow{4}{*}{ 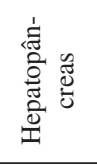 } & \multirow{2}{*}{ Macho } & Média & 2.07 & 110 & $<0.14$ & 6.13 & 0.18 & 0.23 & 44.3 & 1.66 & 0.54 \\
\hline & & & Min -Max & $0.74-3.96$ & $75.2-163$ & --- & 2.01-11.5 & $<0.12-0.72$ & $<0.22-0.36$ & $21.3-65.1$ & $0.62-5.25$ & $<0.15-1.31$ \\
\hline & & \multirow{2}{*}{ Fêmea } & Média & 2.23 & 112 & 0.16 & 19.9 & 0.23 & 0.32 & 72.7 & 2.03 & $<0.15$ \\
\hline & & & Min -Max & $1.12-3.05$ & $88.7-154$ & $<0.14-0.35$ & $11.2-34.9$ & $0.11-0.58$ & $<0.22-0.48$ & $56.1-102$ & $0.37-4.68$ & $<0.15-1.14$ \\
\hline & \multirow{4}{*}{ 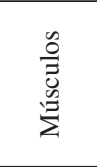 } & \multirow{2}{*}{ Macho } & Média & 16.5 & 59.6 & $<0.14$ & 1.72 & $<0.12$ & $<0.22$ & 121 & $<0.21$ & $<0.15$ \\
\hline & & & Min -Max & $11.9-22.3$ & 48.4-61.4 & --- & $0.33-3.08$ & --- & --- & $109-124$ & --- & --- \\
\hline & & \multirow{2}{*}{ Fêmea } & Média & 13.3 & 44.2 & $<0.14$ & 3.08 & $<0.12$ & $<0.22$ & 111 & $<0.21$ & $<0.15$ \\
\hline & & & Min -Max & $13.0-31.0$ & $51.6-66.8$ & --- & $1.04-4.19$ & --- & --- & $107-128$ & --- & --- \\
\hline \multirow{12}{*}{ 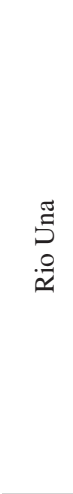 } & \multirow{4}{*}{ : } & \multirow{2}{*}{ Macho } & Média & 7.01 & 157 & 1.36 & 37.8 & 2.47 & 16.7 & 41.7 & 4.04 & 3.55 \\
\hline & & & Min -Max & $5.78-9.10$ & 123-191 & $0.76-2.91$ & $20.1-130$ & $1.27-5.56$ & $5.21-23.4$ & $37.8-43.7$ & $2.36-5.57$ & $1.19-5.34$ \\
\hline & & \multirow{2}{*}{ Fêmea } & Média & 6.68 & 142 & 1.04 & 49.8 & 1.69 & 14.8 & 42.5 & 3.86 & 2.59 \\
\hline & & & Min -Max & $5.17-7.97$ & $113-188$ & $0.58-1.42$ & 27.5-101 & $0.77-2.52$ & $7.39-24.0$ & $39.0-46.1$ & $2.77-5.03$ & $1.16-4.15$ \\
\hline & \multirow{4}{*}{ 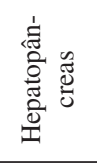 } & \multirow{2}{*}{ Macho } & Média & 2.07 & 110 & 0.15 & 7.87 & 0.12 & 0.31 & 44.3 & 2.54 & 0.55 \\
\hline & & & Min -Max & $0.86-4.53$ & $46.8-222$ & $<0.14-0.77$ & $3.18-12.4$ & $<0.12-0.42$ & $0.18-0.40$ & $24.8-53.2$ & $0.54-8.45$ & $0.26-0.91$ \\
\hline & & \multirow{2}{*}{ Fêmea } & Média & 1.83 & 83.0 & $<0.14$ & 18.9 & 0.18 & 0.31 & 57.0 & 1.66 & 0.54 \\
\hline & & & Min -Max & $1.19-3.53$ & 54.3-113 & $<0.14-0.44$ & $12.8-29.5$ & $<0.12-0.50$ & $0.17-0.39$ & $39.8-92.2$ & $0.64-4.63$ & $<0.15-0.97$ \\
\hline & \multirow{4}{*}{ 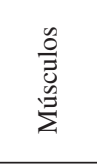 } & \multirow{2}{*}{ Macho } & Média & 19.4 & 65.6 & $<0.14$ & 2.77 & $<0.12$ & $<0.22$ & 116 & $<0.21$ & $<0.15$ \\
\hline & & & Min -Max & $11.4-24.3$ & $48.1-71.5$ & --- & $1.85-6.22$ & --- & --- & $117-125$ & -- & --- \\
\hline & & F̂ิmo & Média & 14.3 & 48.1 & $<0.14$ & 4.08 & $<0.12$ & $<0.22$ & 121 & $<0.21$ & $<0.15$ \\
\hline & & emea & Min -Max & $7.79-24.3$ & $35.3-59.0$ & --- & $2.12-6.22$ & --- & --- & $90.0-125$ & --- & --- \\
\hline & & & Média & 9.55 & 209 & 1.30 & 52.0 & 2.10 & 9.34 & 40.6 & 3.29 & 3.33 \\
\hline & $\cdot \stackrel{\frac{\pi}{3}}{\sigma}$ & lacno & Min -Max & $6.27-13.2$ & $129-231$ & $0.58-1.89$ & $16.5-103$ & $1.16-2.49$ & $6.66-11.7$ & $20.2-58.2$ & $2.74-4.01$ & $2.02-5.38$ \\
\hline & 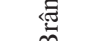 & - & Média & 8.71 & 191 & 1.66 & 56.9 & 2.44 & 12.7 & 42.5 & 3.59 & 3.65 \\
\hline & & emed & Min -Max & $6.99-9.92$ & $99.4-243$ & $0.96-2.41$ & $19.42-114.91$ & $1.90-2.76$ & $9.06-17.0$ & $43.3-73.1$ & $2.47-4.25$ & $2.30-4.83$ \\
\hline ప & & Macho & Média & 4.24 & 177 & 0.22 & 6.36 & $<0.12$ & 0.19 & 39.8 & 3.92 & 0.39 \\
\hline.$\Xi$ & 贾 : & Iviacino & Min -Max & $2.09-6.77$ & $175-232$ & $<0.14-0.92$ & $19.4-115$ & --- & $<0.22-0.40$ & $36.1-49.8$ & 0.78-10.66 & $<0.15-0.93$ \\
\hline ప్రి & क्षे & Fêmea & Média & 4.91 & 167 & 0.59 & 27.1 & 0.50 & 0.34 & 57.1 & 4.17 & 0.61 \\
\hline $\overrightarrow{0}$ & & remea & Min -Max & $2.22-7.57$ & $167-229$ & $0.16-0.97$ & $11.2-59.0$ & $<0.12-1.18$ & $0.29-0.40$ & $39.2-44.4$ & $1.69-9.74$ & $0.46-0.78$ \\
\hline a & & Aroho & Média & 17.0 & 55.1 & $<0.14$ & 1.04 & $<0.12$ & $<0.22$ & 115 & $<0.21$ & $<0.15$ \\
\hline & $\frac{0}{3}$ & Tacno & Min -Max & $12.3-28.2$ & $48.1-71.5$ & --- & 1.04-1.08 & --- & --- & $111-123$ & --- & --- \\
\hline & 象 & & Média & 13.3 & 48.1 & $<0.14$ & 1.8 & $<0.12$ & $<0.22$ & 117 & $<0.21$ & $<0.15$ \\
\hline & & III & Min -Max & $9.33-17.4$ & $36.2-59.6$ & --- & $0.72-4.15$ & --- & --- & $112-124$ & --- & --- \\
\hline
\end{tabular}

do LOQ do método em alguns manguezais. Para todas as amostras nos diferentes tecidos, Cd e Mo estão abaixo do LOQ. As concentrações de $\mathrm{Mn}$ e $\mathrm{Cu}$ foram determinadas entre 0,8 e 209,3 $\mu \mathrm{g} \mathrm{g} \mathrm{g}^{-1}$. As concentrações de $\mathrm{Ba}, \mathrm{V}, \mathrm{Cr}, \mathrm{Co}$, $\mathrm{Ni}$ e $\mathrm{Pb}$ variaram de menor que o LOQ até $22,33 \mu \mathrm{g} \mathrm{g}^{-1}$.

Nos manguezais em estudo, as maiores concentrações médias de $\mathrm{Cr}\left(5,07 \mu \mathrm{g} \mathrm{g}^{-1}\right), \operatorname{Mn}\left(103,2 \mu \mathrm{g} \mathrm{g}^{-1}\right), \mathrm{Pb}\left(4,04 \mu \mathrm{g} \mathrm{g}^{-1}\right)$ e V $\left(20,40 \mu \mathrm{g} \mathrm{g}^{-1}\right)$ foram encontradas nas brânquias das fêmeas do rio Pardo. Os limites de $\mathrm{Pb}$ e $\mathrm{Cd}$ estabelecidos pela $\mathrm{ANVISA}^{28}$ são, respectivamente, 2,0 e $1,0 \mu \mathrm{g} \mathrm{g}^{-1}$. Assim, analisando a Tabela 3, as concentrações desses elementos no hepatopâncreas estão dentro dos limites estabelecidos. Porém, nas brânquias, o valor de $\mathrm{Pb}$ está um pouco acima do permitido (Una - 3,08 $\mu \mathrm{g} \mathrm{g}^{-1}$ e Jequitinhonha - 3,49 $\mu \mathrm{g} \mathrm{g}^{-1}$ ) e o Cd está abaixo. Para Carvalho et al.,$^{29} \mathrm{o} \mathrm{Pb}$, por ser uma substância tóxica em altas doses, pode causar efeitos fisiológicos negativos para o organismo humano, podendo provocar morte ou danos mais graves na função cerebral e em outros órgãos. O grau de toxicidade vai depender da duração em que o organismo ficou exposto, assim como o nível do contaminante..$^{29}$
Através da análise de variância, observou-se que somente os resultados de Mn no hepatopâncreas são estatisticamente diferentes ( $\mathrm{p}<0,05)$ entre machos e fêmeas, nos três estuários estudados. A concentração de Mn nas fêmeas dos estuários estudados foi 1.5 a 4.2 vezes maior que nos machos. De acordo com Miramand et al. ${ }^{30}$ as elevadas concentrações de Mn nas fêmeas está relacionada com a dieta enrriquecida no elemento durante a reprodução. Além disso, as fêmeas que carregam ovos fertilizados por mais de um mês necessitam estocar mais micronutrientes. ${ }^{31}$

Foram determinados elevados teores de $\mathrm{Cu}\left(23,6\right.$ - 209,3 $\left.\mu \mathrm{g} \mathrm{g}^{-1}\right)$ e Zn (39,8 - 120,7 $\left.\mu \mathrm{g} \mathrm{g}^{-1}\right)$ nos indivíduos coletados nas três áreas de estudo. Os elementos $\mathrm{Zn}$ e $\mathrm{Cu}$ são micronutrientes essenciais para crustáceos decápodes. O primeiro é usado como ativador de sistemas enzimáticos, enquanto o $\mathrm{Cu}$ é utilizado como parte integrante do pigmento respiratório hemocianina. Mesmo sendo o $\mathrm{Cu}$ um micropigmento importante para os crustáceos Decápodes, ${ }^{32} \mathrm{o}$ acúmulo de elementos traço afeta o seu metabolismo devido à necessidade de maior energia gasta com a excreção e desintoxicação desses elementos. 
No presente estudo, os teores de $\mathrm{Cu}$ em todos os tecidos encontram-se acima dos valores estabelecidos pela ANVISA, ${ }^{33}$ que é de $30 \mu \mathrm{g} \mathrm{g}^{-1}$, podendo representar alteração na concentração desse analito no ambiente, além da toxicidade para os indivíduos que se alimentam do hepatopâncreas e do tecido muscular.

Os valores permitidos para $\mathrm{Cr}$, Ni e $\mathrm{Zn}$ são, respectivamente, $0,1 \mu \mathrm{g} \mathrm{g}^{-1} ; 5,0 \mu \mathrm{g} \mathrm{g}^{-1}$ e 50,0 $\mu \mathrm{g} \mathrm{g} \mathrm{g}^{-1} \cdot{ }^{33} \mathrm{~A}$ concentração de Zn está acima do limite nos três tecidos estudados, já as concentrações de $\mathrm{Cr}$ e Ni no hepatopâncreas e no tecido muscular estão abaixo do permitido; nas brânquias está acima do limite estabelecido. A exposição ao Zn em altas quantidades pode causar dores de estômago, irritações de pele, distúrbios no metabolismo de proteínas e quando a exposição ocorre em grandes quantidades por períodos prolongados, pode haver a ocorrência de anemia e esterilidade. ${ }^{34}$ Mesmo sendo um elemento traço essencial para os caranguejos, em níveis elevados pode ser tóxico, ${ }^{35}$ podendo acarretar grandes prejuízos para a saúde do organismo, como causar retardo no crescimento, bem como redução do consumo de oxigênio. ${ }^{36,37}$ Para os demais elementos, não foram encontrados valores orientadores na legislação.

Os analitos estudados exibiram um padrão de distribuição, na seguinte ordem decrescente de concentração nas brânquias: $\mathrm{Cu}>\mathrm{Mn}$ $>\mathrm{Zn}>\mathrm{V}>\mathrm{Ba}>\mathrm{Cr}>\mathrm{Pb}>\mathrm{Ni}>\mathrm{Co}$; nos hepatopâncreas: $\mathrm{Cu}>\mathrm{Zn}>$ $\mathrm{Mn}>\mathrm{Ba}>\mathrm{Cr}>\mathrm{Pb}>\mathrm{V}>\mathrm{Ni}>\mathrm{Co}$; e no tecido muscular $\mathrm{Zn}>\mathrm{Cu}>$ $\mathrm{Ba}>\mathrm{Mn}$, sendo $\mathrm{Cr}, \mathrm{Co}, \mathrm{Ni}, \mathrm{Pb}$ e V menores que LOQ. De modo geral, maiores teores dos elementos foram determinados nas brânquias, em seguida hepatopâncreas e músculo, nas três áreas em estudo.

De acordo com Reed et al. ${ }^{38}$ os maiores teores de metais são determinados nos hepatopâncreas devido à sua função desintoxicadora. Porém, no presente estudo, os maiores teores de metais essenciais ou não-essenciais foram determinados nas brânquias. As altas concentrações nas brânquias já eram esperadas, visto que os elementos traço presentes no ambiente são adsorvidos primeiramente pelas brânquias, por apresentarem uma alta permeabilidade. ${ }^{39}$ Viswanathan et al. ${ }^{40}$ também concluíram que as brânquias dos $P$. pelagicus do estuário Ennore (Índia) possuem concentrações de metais pesados mais altas do que músculos e hepatopâncreas. De acordo com os referidos autores, as brânquias estão em contato direto com a água circundante, o que favorece o seu enriquecimento com contaminantes.

Avaliando a diferença de concentração entre os sexos nos diferentes tecidos, observou-se, de acordo com a ANOVA, que não há distinção de sexo nos tecidos em estudo, ou seja, $p>0,05$. Segundo Mantelatto e Christofoletti, ${ }^{41}$ os caranguejos na fase jovem possuem uma dieta diferente dos organismos na fase adulta. Em contrapartida, segundo Mantelatto, ${ }^{42}$ machos e fêmeas da mesma espécie possuem uma dieta semelhante, porém, devido à pequena malha amostral do presente estudo $(n=10)$ não foi possível identificar diferenças nas concentrações entre machos e fêmeas. Esse autor pôde constatar que existe similaridade na dieta entre fêmeas e machos, provavelmente, como já dito anteriormente, devido à ocupação do mesmo habitat durante grande parte da vida.

Esse estudo foi comparado com outros trabalhos que utilizaram os mesmos tecidos para avaliar os riscos de elementos presentes no meio ambiente, como pode ser visto na Tabela 5. Pela ANVISA ${ }^{28,33}$ foram analisadas as concentrações de $\mathrm{Cu}, \mathrm{Ni}, \mathrm{Zn}, \mathrm{Cr}$ e $\mathrm{Pb}$ permitidas para o consumo humano sem um tecido específico. $\mathrm{O}$ valor permitido segundo a ANVISA para Cu é de $30,0 \mu \mathrm{g} \mathrm{g}^{-1} \mathrm{e}$ em todas as amostras analisadas o valor encontrado foi superior ao permitido, em contrapartida, todos os valores de Ni estavam abaixo do permitido pela ANVISA, 5,0 $\mu \mathrm{g} \mathrm{g}^{-1}$. Os valores de $\mathrm{Zn}, \mathrm{Cr}$ e $\mathrm{Pb}$ não tiveram os valores com comportamentos padrões como os citados anteriormente. Para o Zn, todas as amostras de músculos analisadas estavam com os níveis mais elevados do que os estimados e os de hepatopâncreas estavam maiores em Una e Jequitinhonha. $\mathrm{O} \mathrm{Cr}$ teve todos os valores no tecido muscular inferior ao permitido, mas já as concentrações nas brânquias e hepatopâncreas estavam superiores. Já para o elemento $\mathrm{Pb}$, as concentrações nas brânquias estavam maiores que o estimado pela ANVISA e no músculo e hepatopâncreas estavam abaixo. Jiang et $\mathrm{al}^{2}$ analisaram brânquias, hepatopâncreas e músculo em um caranguejo no Nordeste da China para determinar os teores de $\mathrm{Cu}, \mathrm{Zn}$ e $\mathrm{Pb}$. As concentrações encontradas de $\mathrm{Cu}$ foram superiores às encontradas no presente estudo e, para $\mathrm{Zn}$, o presente estudo teve teor menor no musculo. Já para o $\mathrm{Pb}$, em ambos os estudos, foram encontrados valores $<0,10$ no músculo. Esse trabalho também foi comparado ao realizado por Peng et al. ${ }^{43}$ que avaliaram a bioacumulação de vestígios de $\mathrm{Cu}, \mathrm{Co}, \mathrm{Mn}, \mathrm{Ni}, \mathrm{Zn}, \mathrm{Cr}$ e $\mathrm{Pb}$ no caranguejo submarino hidrotermal Xerograpsus testudinatus na ilha de Kueishan, Taiwan e encontraram para o $\mathrm{Cu}$ concentrações menores do que o presente estudo no hepatopâncreas, enquanto que o presente estudo teve para Co teores mais elevados nas brânquias e mais baixos no músculo. As concentrações de Mn foram menores que o presente estudo em todos os tecidos, contrapondo às encontradas de $\mathrm{Zn}$ que foram maiores também em todos os tecidos. Para o $\mathrm{Cr}$, as concentrações nas brânquias e hepatopâncreas foram superiores aos encontrados por Peng et al. ${ }^{43}$ sendo menores no tecido muscular. As concentrações de $\mathrm{Pb}$ para o Xerograpsus testudinatus nas brânquias foram menores do que os do Goniopsis cruentata, mas no músculo e hepatopâncreas encontrou teores maiores. ${ }^{42}$ Pinheiro et al. ${ }^{44}$ realizaram o monitoramento e genotoxicidade de um mangue no sudeste do Brasil utilizando as brânquias, hepatopâncreas e músculos do Ucides cordatus para determinar as concentrações de $\mathrm{Cu}, \mathrm{Mn}, \mathrm{Cr}$ e $\mathrm{Pb}$. Todos os valores encontrados foram inferiores ao presente estudo, exceto $\mathrm{Mn}$ e $\mathrm{Cr}$ nos músculos de todos os estuários.

Analisando as correlações entre os elementos e os tecidos de brânquias, músculos e hepatopâncreas, constatou-se que as concentrações dos elementos nas diferentes tecidos do G. cruentata nos três manguezais, de um modo geral, não se correlacionam fortemente com os dados biométricos de largura e comprimento da carapaça, e o peso. Assim, esse resultado vem afirmar a ausência de diferença nas concentrações de elementos traço nos ambientes estudados. Esses dados contrastam com o resultado encontrado por Ramos, ${ }^{45}$ que verificou um incremento nas concentrações de Zn, $\mathrm{Cu}$ e $\mathrm{Cd}$ à medida que aumentou a largura da carapaça no tecido muscular ao estudar Callinectes exasperatus. Virga e Geraldo, ${ }^{46}$ ao estudarem siris azuis do gênero Callinectes, certificaram-se de que quanto menor o tamanho do caranguejo, maior é a concentração de elementos traço.

\section{Análise estatística}

A Análise de componentes Principais (PCA) foi realizada com o objetivo de verificar se há correlação entre as concentrações dos elementos determinados com o tipo de tecido, de sexo do Aratu e entre as áreas amostrais. A matriz da PCA foi construída dispondo as 72 amostras de brânquias, hepatopâncreas e músculo de Aratu, de machos e fêmeas, dos três locais de coleta em linhas e as concentrações dos elementos quantificados ( $\mathrm{Ba}, \mathrm{Co}, \mathrm{Cr}, \mathrm{Cu}, \mathrm{Mn}, \mathrm{Ni}$, $\mathrm{Pb}, \mathrm{V}$ e $\mathrm{Zn}$ ) em colunas. As duas primeiras componentes principais são suficientes para explicar a distribuição das amostras de acordo com suas composições de elementos traço. Juntas, PC 1 e PC 2, são capazes de explicar $88,44 \%$ da variância acumulada dos dados. Sendo que a primeira componente é responsável por explicar $68,79 \%$ da variância, e a segunda componente contém $19,65 \%$ da variabilidade dos dados.

As concentrações de quase todos os elementos analisados mostraram-se com valores de pesos elevados e sinal positivo, exceto $\mathrm{Ba}$ e $\mathrm{Zn}$, que apresentaram valores de pesos negativos na PC 1. A 
concentração dos referidos elementos apresentou peso elevado com sinal negativo na PC 2. Essa distribuição espacial das variáveis nos eixos da PC 1 versus a PC 2 pode ser melhor visualizada no gráfico de pesos representado na Figura 2.

Examinado a Figura 2b, pode-se observar que as amostras foram separadas em três grupos distintos, de acordo as composições elementares características de cada tipo de tecido analisado. As amostras de brânquias são caracterizadas pelas altas concentracões dos elementos $\mathrm{Co}, \mathrm{Cr}, \mathrm{Cu}, \mathrm{Ni}, \mathrm{Pb}, \mathrm{V}$ e Mn. Já as amostras de músculos se caracterizam por altas concentracões de Ba e baixas concentracões de $\mathrm{Zn}$, comparativamente com os outros tecidos analisados.

As brânquias, hepatopâncreas e músculos exercem funções diferentes no organismo, portanto, podem absorver analitos diferentes e, consequentemente, a magnitude em que se apresentam. Somado a isso, têm-se que a concentração difere em função de cada metal, dependendo desse ser essencial ou não à fisiologia do animal. ${ }^{12}$ Para elementos que não exercem função biológica, eles não são controlados, sendo acumulados em proporção à sua disponibilidade no meio. ${ }^{47-50}$

Observa-se também que não foi possível uma distinção entre os sexos dos Aratus, bem como das áreas amostrais, indicando que essas duas variáveis têm características similares. A mobilidade e biodisponibilidade dos metais é influenciada por parâmetros físico-químicos como $\mathrm{pH} .{ }^{23}$ Segundo Celino et al., ${ }^{51}$ os valores médios de $\mathrm{pH}$ determinados nos rios Pardo, Jequitinhonha e Una foram similares, 6,8; 6,9 e 6,7, respectivamente. Assim, como o baixo $\mathrm{pH}$ da água favorece uma maior dissolução dos íons ${ }^{52}$ e essas áreas compartilham de características químicas semelhantes, isso pode justificar a não distinção das áreas nos resultados encontrados. Similarmente, Escobar et al. ${ }^{19}$ ao estudarem elementos traço na água superficial, material particulado em suspensão e no sedimento de fundo nessa região, verificaram que existem semelhanças nos níveis de elementos traço nas três áreas de estudo para os diferentes compartimentos ambientais.
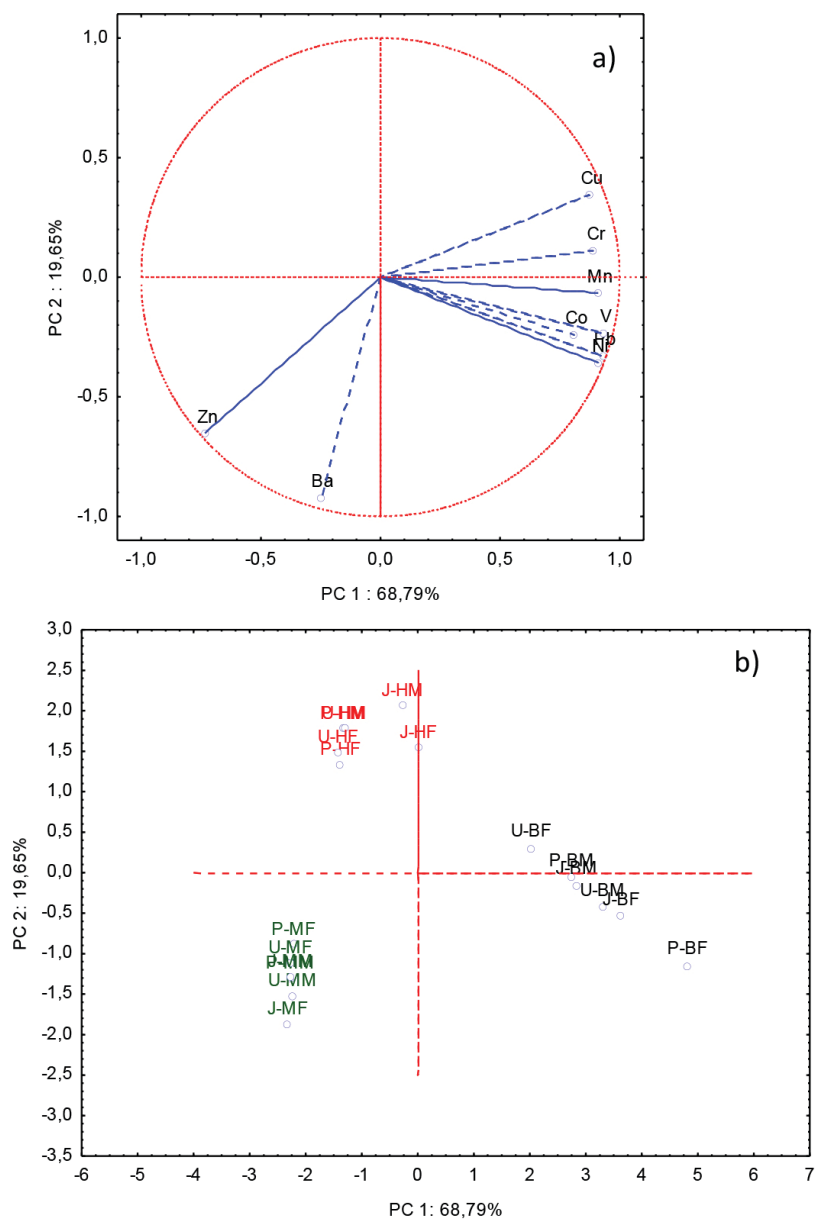

Figura 2. Gráfico de Análise de Componentes Principais. a) $P C 1 \times P C 2$ dos elementos traço, b) $\mathrm{PC} 1 \times \mathrm{PC} 2$ dos tecidos de caranguejos analisados

Tabela 5. Médias das concentrações dos elementos traço determinados em tecidos do caranguejo G. cruentata (seis fêmeas e seis machos para cada matriz; $\mathrm{n}=12$ ) coletados nos manguezais dos estuários dos rios Una, Pardo e Jequitinhonha, comparados com valores permitidos pela ANVISA (1965/ 1998) e com outros trabalhos

\begin{tabular}{|c|c|c|c|c|c|c|c|c|c|c|}
\hline \multirow{2}{*}{ Referência } & \multirow{2}{*}{ Variáveis usadas } & \multicolumn{9}{|c|}{ Concentração $\left(\mathrm{mg} \mathrm{g}^{-1}\right)$} \\
\hline & & $\mathbf{B a}$ & $\mathbf{C u}$ & Co & Mn & $\mathbf{N i}$ & $\mathbf{V}$ & Zn & $\mathrm{Cr}$ & $\mathbf{P b}$ \\
\hline \multirow{3}{*}{$\begin{array}{l}\text { Presente trabalho } \\
\text { Rio Una }\end{array}$} & Brânquias & 10.8 & 191 & 1.35 & 71.4 & 2.46 & 17.7 & 44.6 & 4.95 & 3.54 \\
\hline & Hepatopâncreas & 2.15 & 111 & 0.16 & 13.0 & 0.21 & 0.28 & 58.5 & 1.85 & 0.54 \\
\hline & Músculos & 14.9 & 51.9 & $<0.14$ & 2.4 & $<0.12$ & $<0.22$ & 116 & $<0.21$ & $<0.15$ \\
\hline \multirow{3}{*}{$\begin{array}{l}\text { Presente trabalho } \\
\text { Rio Jequitinhonha }\end{array}$} & Brânquias & 6.85 & 150 & 1.20 & 43.8 & 2.08 & 15.8 & 42.1 & 3.95 & 3.07 \\
\hline & Hepatopâncreas & 1.95 & 96.3 & 0.14 & 13.4 & 0.15 & 0.31 & 50.7 & 2.10 & 0.55 \\
\hline & Músculos & 16.8 & 56.9 & $<0.14$ & 3.42 & $<0.12$ & $<0.22$ & 118.58 & $<0.21$ & $<0.15$ \\
\hline \multirow{3}{*}{$\begin{array}{l}\text { Presente trabalho } \\
\text { Rio Pardo }\end{array}$} & Brânquias & 9.13 & 200 & 1.48 & 54.5 & 2.27 & 11.0 & 41.6 & 3.44 & 3.49 \\
\hline & Hepatopâncreas & 4.58 & 172 & 0.41 & 16.7 & 0.50 & 0.27 & 48.5 & 4.05 & 0.50 \\
\hline & Músculos & 15.2 & 51.6 & $<0.14$ & 1.42 & $<0.12$ & $<0.22$ & 116 & $<0.21$ & $<0.15$ \\
\hline ANVISA $^{33}$ & $*$ & $\mathrm{NE}$ & 5.0 & $\mathrm{NE}$ & $\mathrm{NE}$ & 30.0 & $\mathrm{NE}$ & 50.0 & 0.1 & 2.0 \\
\hline \multirow[t]{2}{*}{ ANVISA $^{28}$} & $*$ & & $\mathrm{NE}$ & & & $\mathrm{NE}$ & & $\mathrm{NE}$ & $\mathrm{NE}$ & 2.0 \\
\hline & Brânquias & NA & 39.2 & NA & NA & NA & NA & 9.65 & NA & 0.18 \\
\hline \multirow[t]{3}{*}{ Jiang et al. ${ }^{2}$} & Hepatopâncreas & & 2.68 & & & & & 93.6 & & $<0.15$ \\
\hline & Músculos & & 10.3 & & & & & 76.56 & & $<0.15$ \\
\hline & Brânquias & NA & 290 & 0.67 & 3.31 & 4.96 & NA & 610 & 2.17 & 2.28 \\
\hline \multirow[t]{3}{*}{ Peng et al. ${ }^{42}$} & Hepatopâncreas & & 53.8 & 0.20 & 3.95 & 1.64 & & 118 & 1.66 & 2.64 \\
\hline & Músculos & & 74.6 & $<0.14$ & 0.69 & 0.99 & & 230 & 0.81 & 1.83 \\
\hline & Brânquias & NA & 22.4 & NA & 8.01 & NA & NA & NA & 0.37 & $<0.36$ \\
\hline \multirow[t]{2}{*}{ Pinheiro et al. ${ }^{43}$} & Hepatopâncreas & & 6.64 & & 8.89 & & & & 0.52 & \\
\hline & Músculos & & 5.31 & & 5.09 & & & & 0.25 & \\
\hline
\end{tabular}

NA: não analisado; NE: não estudado. 


\section{Avaliação do potencial de risco pelo consumo de Goniopsis} cruentata

Metais como o $\mathrm{Zn}, \mathrm{Cu}$ e o $\mathrm{Mn}$, por serem essenciais para o metabolismo e imunidade do corpo humano, são encontrados em teores elevados, no entanto, quando essas concentrações ultrapassam o limite necessário para a regulação e processos, podem trazer prejuízos para os diversos sistemas que compõem o corpo humano. ${ }^{53}$ Assim, foi avaliado o potencial de risco de elementos traço para a saúde a partir do consumo do caranguejo Goniopsis cruentata. Para o estudo, foi usado apenas o tecido muscular, visto que o músculo do caranguejo é o tecido mais consumido pelos brasileiros.

O risco potencial ${ }^{54}$ foi avaliado através da ingestão diária estimada (IDE) e do quociente de risco (QR) e podem ser encontrados na Tabela 6. O IDE faz uma relação entre a concentração do elemento no tecido do caranguejo $\left(\mathrm{C}_{\text {Aratu }}\right)$, o consumo diário $\left(\mathrm{CD}_{\text {Aratu }}\right)$ e o peso dos adultos consumidores (PA) (Equação 1). O QR foi calculado (Equação 2) utilizando o IDE encontrado e a dose de referência (DRf) estimada pela USEPA. ${ }^{22}$ Dos nove elementos analisados no estudo, foi avaliado o risco para apenas três elementos ( $\mathrm{Mn}, \mathrm{Cu}$ e $\mathrm{Zn}$ ), pois possuem valor de DRf disponível na literatura.

$$
\begin{gathered}
\mathrm{IDE}=\left(\mathrm{C}_{\text {Aratu }} \times \mathrm{CD}_{\text {Aratu }}\right) / \mathrm{PA} \\
\mathrm{QR}=\mathrm{IDE} / \mathrm{DRF}
\end{gathered}
$$

Utilizou-se o consumo diário de pescados para realização dos cálculos, visto que na legislação brasileira não há taxa de ingestão para crustáceo. Neste estudo aplicou-se a taxa de ingestão ou consumo de $35 \mathrm{~g} /$ habitante/dia (12,77 kg/habitante/ ano). ${ }^{55}$ De acordo com o IBGE, ${ }^{56}$ o peso corporal médio de um adulto brasileiro é, aproximadamente, $63 \mathrm{~kg}$. As concentrações médias de cada elemento nos três estuários (Una, Pardo e Jequitinhonha) foi obtida a partir da média de machos e fêmeas nos seis sítios de coleta, sendo para Zn, $\mathrm{Mn}$ e Cu no rio Una, respectivamente, 116,03; 2,64 e 51,89 $\mu \mathrm{g} \mathrm{g}^{-1}$, para o rio Pardo, 116,36; 2,27 e 58,27 $\mu \mathrm{g} \mathrm{g}^{-1}$ e para o rio Jequitinhonha 115,81 ; 1,01 e $56,88 \mu \mathrm{g} \mathrm{g}^{-1}$. Os valores de IDE para $\mathrm{Cu}, \mathrm{Zn}$ e Mn do Goniopsis cruentata foram no intervalo de $1,01-116,36 \times 10^{-3} \mu \mathrm{g} \mathrm{kg} \mathrm{peso}^{-1} \mathrm{dia}$, como pode ser visto na Tabela 6.

Os valores de IDE dos elementos essenciais para os crustáceos tiveram o mesmo comportamento nos três estuários, sendo os valores do $\mathrm{Zn}$ e $\mathrm{Cu}$ expressivamente maiores do que o do $\mathrm{Mn}$. Em Una, o IDE do $\mathrm{Zn}, \mathrm{Cu}$ e $\mathrm{Mn}$ foi respectivamente 64,21; 28,71 e
$1,77 \mu \mathrm{g} \mathrm{kg} \mathrm{peso-1} \mathrm{dia}^{-1}$. Em Pardo, o IDE do Zn, Cu e Mn foi respectivamente, 64,39; 32,24 e 1,26 $\mu \mathrm{g} \mathrm{kg} \cdot$ peso $^{-1} \mathrm{dia}^{-1}$. No rio Jequitinhonha, as concentrações para Zn, Cu e Mn foram, respectivamente, 64,40; 31,48 e $0,94 \mu \mathrm{g} \mathrm{kg}$ peso $^{-1} \mathrm{dia}^{-1}$. Os valores de IDE estão menores do que o valor de DRf, indicando que o consumo do caranguejo Goniopsis cruentata coletados nos estuários dos rios Una, Jequitinhonha e Pardo, não implica risco à saúde humana.

O QR tem sido muito utilizado por muitos pesquisadores como ferramenta para avaliar o risco de vestígios de metais a partir do consumo de frutos do mar, incluindo mariscos e peixes. O $\mathrm{QR} \leq 1$ não indica risco para a saúde. ${ }^{54} \mathrm{Em}$ virtude dessa utilização, o coeficiente de risco também foi empregado para avaliar o risco de saúde para os consumidores do Goniopsis cruentata capturados no Sul da Bahia como outro critério que venha a ratificar o resultado encontrado com IDE. Os valores calculados de QR estão expostos na Tabela 6.

Os valores encontrados no QR tiveram o mesmo comportamento nos três estuários, mas diferente do comportamento dos valores de IDE. No rio Una para $\mathrm{Zn}, \mathrm{Cu}$ e $\mathrm{Mn}$ são, respectivamente, 0,21; 0,72 e 0,01 . Para o estuário do rio Pardo os valores de encontrados de $\mathrm{Zn}, \mathrm{Cu}$ e Mn são, respectivamente 0,$21 ; 0,81$ e 0,01. Os valores no rio Jequitinhonha para $\mathrm{Zn}, \mathrm{Cu}$ e $\mathrm{Mn}$, são respectivamente 0,21 ; 0,79 e 0,01 .

$\mathrm{Gu}$ et al, ${ }^{17}$ ao estudarem as concentrações de metais pesados em peixes selvagens capturados do Sul do Mar da China e riscos para a saúde associados, concluíram, com exceção para Fe e Mn, que as concentrações de metais pesados foram inferiores aos limites máximos diários aceitáveis. A avaliação do risco para a saúde humana, no entanto, indicou que os riscos para a saúde humana da exposição a metais pesados através do consumo destes peixes selvagens marinhos são insignificantes. Ao estudar as concentrações de metais nos tecidos de caranguejos Chionoecetes (Chionoecetes japonicus e Chionoecetes opilio) coletados nas águas do mar do Leste do Japão, Hwang et al. ${ }^{54}$ estimaram, usando limites regulatórios (IDE), que o consumo máximo admissível diário de $C$. japonicus e $C$. opilio é, aproximadamente, 240 e $410 \mathrm{~g} \mathrm{dia}^{-1}$, respectivamente, sendo necessário no futuro legislações que regulamentem a ingestão de caranguejos Chionoecetes.

No presente estudo, todos os valores de QR estão inferiores a 1,0, implicando que a ingestão desses elementos através do consumo do Aratu não representa perigo para os seres humanos, visto que, além dos baixos valores de IDE e QR, o consumo semanal de $\sim 35 \mathrm{~g} \mathrm{dia}^{-1}$ é referente ao consumo de pescado, sendo o consumo de caranguejo menor que este valor. Porém, observa-se que o QR para o $\mathrm{Cu}$ é

\begin{tabular}{|c|c|c|c|c|c|c|}
\hline Local & $\begin{array}{l}\text { Elemento } \\
\text { traço }\end{array}$ & $\begin{array}{l}\text { Concentração } \\
\text { média }\left(\mathrm{mg} \mathrm{g}^{-1}\right)\end{array}$ & $\begin{array}{c}\text { Consumo diário } \\
\qquad\left(\mathrm{g} \mathrm{dia}^{-1}\right)\end{array}$ & $\begin{array}{c}\mathrm{IDE}^{\mathrm{b}} \\
\left(\mathrm{mg} \mathrm{kg} \mathrm{peso}^{-1} \mathrm{dia}^{-1}\right)\end{array}$ & $\begin{array}{c}\mathrm{DRf}^{\mathrm{c}} \\
\left(\mathrm{mg} \mathrm{kg}^{-1} \mathrm{dia}^{-1}\right)\end{array}$ & $\begin{array}{l}\text { Quociente de poten- } \\
\text { cial de risco }(\mathrm{QR})\end{array}$ \\
\hline & $\mathrm{Mn}$ & 3.19 & 35 & 1.77 & 140 & 0.013 \\
\hline \multirow[t]{3}{*}{ Rio Una } & $\mathrm{Zn}$ & 116 & & 64.2 & 300 & 0.214 \\
\hline & $\mathrm{Cu}$ & 51.9 & & 28.7 & 40 & 0.718 \\
\hline & $\mathrm{Mn}$ & 2.27 & & 1.26 & 140 & 0.009 \\
\hline \multirow[t]{3}{*}{ Rio Pardo } & $\mathrm{Zn}$ & 116 & & 64.1 & 300 & 0.214 \\
\hline & $\mathrm{Cu}$ & 58.3 & & 32.2 & 40 & 0.806 \\
\hline & $\mathrm{Mn}$ & 1.69 & & 0.94 & 140 & 0.007 \\
\hline \multirow[t]{2}{*}{ Rio Jequitinhonha } & $\mathrm{Zn}$ & 116 & & 64.4 & 300 & 0.215 \\
\hline & $\mathrm{Cu}$ & 56.9 & & 31.5 & 40 & 0.787 \\
\hline
\end{tabular}

Tabela 6. Potencial de risco dos elementos traço ( $\mathrm{Mn}, \mathrm{Zn}$ and $\mathrm{Cu}$ ) no consumo de músculo de caranguejos G. cruentata coletados nos manguezais do Sul da Bahia

${ }^{a}$ Consumo diário de peixe reportado por Silva ${ }^{54}$ que corresponde ao consumo per capta aparente de $12.77 \mathrm{~kg} /$ habitante / ano; ${ }^{\mathrm{b}}$ IDE: Consumo diário estimado calculado a partir da concentração média de elementos traço no músculo do G. cruentata, consumo de peixe diário, e peso médio de adultos Brasileiros ( 63 kg); 56 'DRf: Dose de referência sugerida pelo Sistema de Informação de Risco Integrado (IRIS do inglês, Integrated Risk Information System), da Agência Americana de Proteção Ambiental (USEPA, United States Environmental Protection Agency). ${ }^{22}$ 
próximo da unidade. Embora seja um elemento essencial, excesso desse elemento no organismo pode causar efeitos tóxicos, como a doença de Wilson, também chamada de degeneração hepatocelular, uma enfermidade causada por uma mutação autossômica recessiva no cromossomo 13, que se manifesta produzindo toxicidade devido ao excesso da acumulação de $\mathrm{Cu}$ predominantemente no fígado, no cérebro, com menos extensão nos rins olhos e outros órgãos. ${ }^{57}$

\section{CONCLUSÕES}

A concentração de elementos traço ( $\mathrm{Ba}, \mathrm{Co}, \mathrm{Cr}, \mathrm{Cu}, \mathrm{Mn}, \mathrm{Ni}, \mathrm{Pb}$, $\mathrm{V}$ e Zn) foi determinada nos músculos, brânquias e hepatopâncreas do G. cruentata em três diferentes estuários (Una, Pardo e Jequitinhonha) da região Sul da Bahia. Elevadas concentrações de metais foram determinadas nas brânquias, sendo que baixos teores de $\mathrm{Zn}$ e altos teores de $\mathrm{Ba}$ foram determinados no tecido muscular.

As concentrações médias de metais determinadas em G. cruentata foram (em ordem decrescente) $\mathrm{Cu}>\mathrm{Mn}>\mathrm{Zn}>\mathrm{V}>\mathrm{Ba}>\mathrm{Cr}>\mathrm{Pb}$ $>\mathrm{Ni}>\mathrm{Co}$ nas brânquias; $\mathrm{Cu}>\mathrm{Zn}>\mathrm{Mn}>\mathrm{Ba}>\mathrm{Cr}>\mathrm{Pb}>\mathrm{V}>\mathrm{Ni}$ $>$ Co no hepatopâncreas; e $\mathrm{Zn}>\mathrm{Cu}>\mathrm{Ba}>\mathrm{Mn}$ no tecido muscular, sendo $\mathrm{Cr}, \mathrm{Co}, \mathrm{Ni}, \mathrm{Pb}$ e $\mathrm{V}$ menores que LOQ. Além disso, o ICP OES demonstrou-se uma técnica apropriada para a determinação de baixas concentrações de elementos químicos em amostras de tecido de caranguejo. Através da análise do PCA pode-se observar a diferenciação entre os tecidos estudados devido à sua composição elementar. Baseado na avaliação dos resultados do risco potencial à saúde humana devido ao consumo do músculo do caranguejo, usando limites regulatórios IDE e QR, os $G$. cruentata coletados nas áreas de estudo não têm impacto adverso na saúde baiana. A estimativa do QR utilizada neste estudo foi sensível para detectar o potencial risco à saúde humana no consumo de Aratu.

Para a protecão da saúde dos consumidores baianos se faz necessário a regulamentação da ingestão máxima diária do G. cruentata, principalmente considerando que este representa uma das principais fontes de renda e consumo para a população ribeirinha. Em conclusão, a bioacumulação de metais pesados em caranguejos é uma grande preocupação para a saúde em todo o mundo, sendo importante continuar estudos na área para verificar se haverá aumento do potencial risco no consumo do Aratu.

\section{REFERENCIAS}

1. Rouzbahani, M. M.; Iranian Journal of Aquatic Animal Health 2017, 3 , 101.

2. Jiang, Y.; Wu, J.; Yue, X.; Zang, J.; Adv. Mater. Res. 2013, 781, 1745.

3. Meshram, L. N.; Udawant, S. M.; Mishra, P. S.; Int. J. Adv. Res. 2016, 4, 756 .

4. Hosseini, M.; Nabavi, S. M. B.; Pazooki, J.; Parsa, Y.; J. Mar. Sci. Res. Dev. 2014, 4, 145 .

5. Wu, J. P.; Chen, H. C.; Huang, D. J.; Bull. Environ. Contam. Toxicol. 2008, 81,90 .

6. Mandal, P. K.; Mandal, A.; Ahearn, G. A.; J. Exp. Zool. 2003, 297A, 32.

7. Caceci, T.; Neck, K. F.; Sis, R. F.; J. Mar. Biol. Assoc. U. K. 1988, 68, 323.

8. Bhavan, P. S.; Geraldine, P.; Aquat. Toxicol. 2000, 50, 331

9. Corrêa Jr. J. D.; Silva, M. R.; Silva, A. C. B.; Limad, S. M. A.; Malme, O.; Allodi, S.; Aquat. Toxicol. 2005, 73, 139.

10. Bryan, G.; J. Mar. Biol. Assoc. U. K. 1968, 48, 303

11. Ahearn. G. A.; Mandal. P.K.; Mandal, A.; J. Comp. Physiol. B 2004, $174,439$.

12. Jesus, H. C.; Fernandes, L. F. L.; Zandonade, E.; Anjos Jr., E. E.; Gonçalves, R. F.; Marques, F. C.; Reis, L. A.; Romano, C. T.; Teixeira, R. D.; Sad, C. M. S.; Avaliação da contaminação por metais pesados em caranguejos e sedimentos de áreas de manguezal do sistema estuarino de Vitória - ES, Relatório Técnico -Projeto Facitec/PMV-ES, contr. 4985717/2001, Vitória, 2003.

13. Correia, P. R. M.; Ferreira, M. M. C.; Quim. Nova 2007, 30, 481.

14. Santana, G. P.; Barroncas, P. de S. R.; Acta Amazonica 2007, 37, 111.

15. Sousa, R. A.; Borges Neto, W.; Poppi, R. J.; Baccan, N.; Cadore, S.; Quim. Nova 2006, 29, 654.

16. Santos, M. C. F.; Botelho, E. R. O.; Ivo C. T. C.; Boletim Técnico Científico 2001, 9, 87

17. Gu, Y.G.; Lin, Q.; Wang, X. H.; Du, F. Y.; Yu, Z. L.; Huang, H. H.; Mar. Pollut. Bull. 2015, 96, 508.

18. Vasconcelos, A. O.; Celino, J. J. In Avaliação de ambientes costeiros da região sul da Bahia. Geoquímica, petróleo e sociedade; Celino, J. J., Hadlich, G. M., Queiroz, A. F. S., Oliveira, O. M. C., org.; EdUFBA: Salvador, 2014, pp. 17-39.

19. Escobar, N. F. C.; Celino, J. J.; Nascimento, R. A. In Avaliação de ambientes costeiros da região sul da Bahia. Geoquímica, petróleo e sociedade; Celino, J. J., Hadlich, G. M., Queiroz, A. F. S., Oliveira, O. M. C., org.; EdUFBA: Salvador, 2014, pp. 77-98.

20. IUPAC; Spectrochim. Acta B 1978, 33, 242.

21. Onsanit, S.; Ke, C.; Wang, X.; Wang, K-J.; Wang, W-X.; Environ. Pollut. 2010, 158, 1334.

22. https://cfpub.epa.gov/ncea/iris2/atoz.cfm, acessada em julho de 2018.

23. Menezes, A. P. D.; Araújo, M. S. L. C.; Calado, T. C. S.; Nat. Resour. 2012, 2, 37.

24. Pinheiro, M. A. A.; Duarte, L. F. A.; Toledo, T. R.; Adam, M. L.; Torres, R. A.; Environ. Monit. Assess. 2013, 185, 8273.

25. Reis, C. R. G.; Taddei, F. G.; Cobo, V. J.; Acad. Bras. Cienc. 2015, 87, 699.

26. Santos, M. C. F.; Botelho, E. R. O.; Corrêa, F. M.; Almeida, L.; Silva, C. G. M.; Boletim Técnico Científico 2013, 19, 27.

27. AOAC - Association of Official Methods of Analysis; Guidelines for Standard Method Performance Requirements, Appendix F, $19^{\text {th }}$ ed., AOAC: Gaithersburg, 2012.

28. Brasil, Ministério da Saúde, ANVISA - Agência Nacional de Vigilância Sanitária; Portaria n ${ }^{\circ}$ 685, de 27/09/1998, Brasília, 1998.

29. Carvalho, F. M.; Neto, A. M. S.; Tavares, T. M.; Costa, A.C.A.; Chaves, C.D. R.; Nascimento, L. D.; Reis, M. A.; Pan American Journal of Public Health 2003, 13, 1.

30. Miramand, P.; Lafaurie, M.; Fowler, S.W.; Lemaire, O.; Guary, J. C.; Bentley, D.; Sci. Total Environ. 1991, 103, 47.

31. Rainbow, P. S.; Estuarine, Coastal Shelf Sci. 1997, 44, 167.

32. Macfarlane, G. R.; Booth, D. J.; Brown, K. R.; Aquat. Toxicol. 2000, 50, 153.

33. Brasil, Ministério da Saúde, ANVISA - Agência Nacional de Vigilância Sanitária; Decreto n ${ }^{\circ}$ 55.871, de 26/03/1965, Brasília, 1965.

34. https://www.atsdr.cdc.gov/phs/phs.asp?id=1076\&tid=34, acessado em julho de 2018.

35. Phillips, D. J. H.; Rainbow, P.S.; Biomonitoring of Trace Aquatic Contaminants, $2^{\text {nd }}$ ed., Chapman \& Hall: London, 1993.

36. Wu, J. P.; Chen, H. C.; Toxicol. Bull. Environ. Contam. 2005, 74, 234.

37. Barbieri, E.; Ecotoxicology 2009, 18, 312.

38. Reed, L. A.; Pennington, P. L.; Wirth, E.; Mar. Pollut. Bull. 2010, 60, 2297.

39. Menezes, A. P. D.; Araújo, M. S. L. C.; Calado, T. C. S.; Nat. Resour. 2012, 2, 37 .

40. Viswanathan, C.; Azhaguraj, R.; Selvanayagam, M.; Raffi, S. M.; Int. J. Fish. Aquacult. 2013, 3, 1.

41. Mantelatto, F. L. M.; Christofoletti, R. A.; Mar. Biol. 2001, 138, 585.

42. Mantelatto, F. L. M.; Crustacean Iss. 2000, 12, 431.

43. Peng, S. H.; Hung, J. J.; Hwang, J. S.; Mar. Pollut. Bull. 2011, 63, 396

44. Pinheiro, M. A. A.; Duarte, L. F. A.; Toledo, T. R., Adam, M. L.; Torres, R. A.; Environ. Monit. Assess. 2013, 185, 8273. 
45. Ramos, M. A. V.; Dissertação de Mestrado, Universidade do Estado da Bahia, Brasil, 2012.

46. Virga, R. H. P.; Geraldo, L. P.; Ciênc. Tecnol. Aliment. 2008, $28,943$.

47. Mcmeans, B. C.; Borga, K.; Bechtol, W. R.; Higginbotham, D.; Fisk, A. T.; Environ. Pollut. 2007, 148, 281.

48. Kamaruzzaman, B. Y.; Akbar John. B.; Maryam, B. Z.; Jalal, K. C. A.; Shahbuddin, S.; J. Trop. Agric. Sci. 2012, 35, 183.

49. Kojadinovic, J.; Bustamante, P.; Corre, M.; Cosson, R. P.; Arch. Environ. Contam. Toxicol. 2007, 52, 418.

50. Savinov, V. M.; Gabrielsen, G. W.; Savinova, T. N.; Sci. Total Environ. 2003, 306, 133.

51. Meneses, M. L. G. G.; Prost, C.; Anunciação , D. S.; Moraes, S. S.; Jesus, T. B. Em Avaliação de ambientes costeiros da região sul da Bahia. Geoquímica, petróleo e sociedade; Celino, J. J., Hadlich, G. M., Queiroz, A. F. de S., Oliveira, O.M.C., orgs.; EdUFBA: Salvador, 2014, p. 131-136.
52. Salomons, W.; Förstner, U.; Metal in the hydrocycle, Berlin: Springer Verlag, 1984, p. 349.

53. Prashanth, L.; Kattapagari, K. K.; Chitturi, R. T.; Baddam, V. R. R.; Prasad, L. K.; Journal of Dr. NTR University of Health Sciences 2015 , 4,75 .

54. Hwang, D. W.; Choi, M.; Lee, I. S.; Kil-bo Shim, K. B.; Kim, T. H.; Environ. Sci. Pollut. Res. 2017, 24, 11309.

55. Silva, C. A.; Oliveira, S. S.; Avaliação do potencial risco à saúde humana de metais pesados em peixes marinhos consumidos em Aracaju, Maceió e Salvador, Brasil, Boletim de Pesquisa/ Embrapa Tabuleiros Costeiros, Aracaju, 2016.

56. http://g1.globo.com/brasil/noticia/2010/08/metade-dos-adultosbrasileiros-esta-acima-do-peso-segundo-ibge.html, acessado em julho 2018

57. Baierle, M.; Valentini, J.; Paniz, C.; Moro, A.; Junior, F. B.; Garcia, S. C.; J. Bras. Patol. Med. Lab. 2010, 46, 463. 